\title{
Study on Deformation Behavior of Sediments and Applicability of Sealants in Seabed Mining
}

\author{
Takashi Sasaoka ${ }^{1}$, Hiroto Hashikawa ${ }^{1}$, Akihiro Hamanaka $^{1, *}$, Hideki Shimada ${ }^{1}$, Keisuke Takahashi $^{2}$ \\ ${ }^{1}$ Department of Earth Resources Engineering, Faculty of Engineering, Kyushu University, Fukuoka 819-0395, Japan
}

${ }^{2}$ Ube Ind. Ltd, Yamaguchi 755-8633, Japan

\begin{tabular}{l} 
A R T I C L E I N F O \\
\hline Article history: \\
Received: 09 June, 2021 \\
Accepted: 12 July, 2021 \\
Online: 20 July, 2021 \\
\hline Keywords: \\
Rare-Earth \\
Sealing material \\
Submarine Mining \\
Suction mining \\
Surface coverage \\
\end{tabular}

\begin{abstract}
A B S T R A C T
The importance of rare earth resources is increasing and a lot of investigations are conducting all over the world. As a result, it was discovered that abundant deep-sea mud contained rare-earth elements on the deep-sea floor. The suction mining method can be one of the effective seabed mining methods to recover these seafloor sediments. However, it is required to evaluate the deformation behavior of the sediments in seabed mining in terms of environmental evaluation. For this reason, this study investigates the deformation behavior of sediments with different water contents by a laboratory suction test. In the test, the sediments filled in a box whose size is $155 \mathrm{~mm} \times 50 \mathrm{~mm} \times 180 \mathrm{~mm}$ are vacuumed with a suction pump. The suction pressure of the pump is adjusted to $4.0 \mathrm{kPa}$, the diameter of the suction pump is $10 \mathrm{~mm}$, and the duration of suction is 8 seconds. The results show that suction volume increases with an increase of water content/liquid limit ratio. In addition, the deformation behavior can be categorized as three shapes based on water content/liquid limit ratio; sharp, cone-shaped, and gentle circular arc when the ratio of water content/liquid limit is under 1.3, from 1.3 to 1.6, and over 1.6, respectively. Furthermore, the application of sealants on the sediment surface is effective to reduce the environmental disturbance although its density has to be the same level as the density of sediments to inhibit sinking the sealants.
\end{abstract}

\section{Introduction}

The demand for rare mineral resources is growing day by day. Rare earth elements have an important role in modern industry and are used in recent technologies, e.g., electric vehicles, wind turbines, solar panels, rechargeable batteries, mobile phones, a light-emitting diode (LED), and laser system. A lot of investigations are conducted to discover new ore deposits all over the world. The results of various surveys have confirmed the presence of abundant deep-sea mud which contains the rare-earth elements as the seafloor sediments $[1,2]$, meaning that it could be a promising option as a source of supply of rare-earth resources for the future if these untouched resources on the deep seafloor can be recovered. Some heavy machines/systems are introduced for the exploitation of resources of the seabed for digging, collecting, and transportation [3]. Regarding the deep-sea sediment contained the rare-earth elements, suction mining can be preferred as one of the effective methods because the sediments are the aggregation of fine particles and can be suctioned. In addition, the suction mining

*Corresponding Author: Akihiro Hamanaka E-mail: hamanaka@mine.kyushuu.ac.jp

www.astesj.com

https://dx.doi.org/10.25046/aj060420 method has higher applicability than other mining methods using heavy machines when ore deposits exist on and under the deep seafloor. On the other hand, the development of these untouched seabed resources must be carried out considering the environmental impacts on the ecosystem in the sea to protect biodiversity. The development of deep-sea minerals does not still incorporate into society, and local communities care about the environmental impact on the ocean ecosystems due to the lack of investigations [4].

Mining developments in land-based mining such as surface and underground mining causes adverse environmental impacts historically: water pollutions, the impact on groundwater hydraulics and surface topography, the destruction of habitat/ecosystems, and the loss of diversity. These adverse impacts are often the results of poor planning, the inadequate process of environmental remediation, and insufficient inspection after mine closure due to the lack of standard regulations. The regulation of seabed mining is not established yet because there are insufficient baseline data of environment in the deep-sea is lacking [5]. Therefore, various researches have been reported recently in 
terms of the regulations known as 'Mining Code' [5-9]. Several approaches suggested to establish the regulation of deep seabed mining such as adaptive management and utilizing the legal framework in the surface mining reclamation $[10,11]$.

Regarding the suction mining, the hybrid system of air-lift pump combined with the device of dredging using the jet pump is expected to adopt. The air-lift pump is an expected technology to transport the seabed minerals from the deep seafloor, but the extraction of the seafloor sediments with this system may be not efficient. Therefore, another mechanism to extract the sediments requires for the efficient mining system. Some devices have been developed for dredging using a jet pump in the civil engineering field [12-14]. The technology of dredging can be adopted for the extraction of seabed resources. However, it is required to evaluate the deformation behavior of the sediments in seabed mining because it causes suspension and topographic variation. For this reason, it is important to estimate and control the deformation behavior of the sediments in seabed mining. In addition, the impacts on the surrounding environment include the diffusion and redeposition of suspended particles caused by mining. In fact, sediments containing toxic metals such as arsenic have been found near seabed hydrothermal deposits $[15,16]$. Thus, sealants are considered as one of the potential methods to reduce the environmental impact in seabed mining [17]. This study uses cement-based materials as sealants based on ground improvement technology in the civil engineering field. Ground improvement is often used to improve the stability of buildings by solidifying soft ground and making it strong by adding improvement materials. It is also widely used for additives and technologies to immobilization of toxic substances in contaminated soil/ground. Cement-based materials are also adopted to construct offshore structures using underwater concreting. Several kinds of research investigated the properties of cement-based materials in deep-sea conditions and showed the results of the deterioration mechanism due to the microstructural changes with pressurization $[18,19]$

The authors invented an environment-friendly underwater mining method that aims to control the dispersion of seabed surface sediments and fill the extracted areas by sealing a submerged mine site with anti-washout cement-based sealants. That is to say, sealants can restrain suspension by covering the mining area in advance. Figure 1 illustrates the idea of the underwater mining method. This paper discussed the deformation behavior of the sediments which contain the rare-earth elements on the deep sea, and the application of sealants in the suction mining method by means of several laboratory tests.

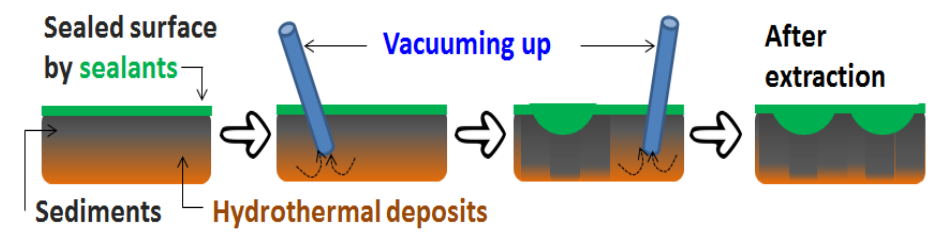

Figure 1: Environment-friendly Submarine Mining

\section{Preparation of Sediment and Suction Test}

\subsection{Sediment Samples}

The sediments contained the rare-earth elements on the deep sea are classified as clay on soil classification according to the previous investigation results by Ministry of Economy, Trade and Industry. The state of sediments is saturated in the seafloor, indicating that the liquid limit and water content can be the related parameters to show their properties. However, the liquid limit and water content of the sediments are different depending on the place as shown in Table 1, indicating that it is expected that these differences affect the deformation behavior of the sediments on suction mining. Therefore, some sediment samples which had a different liquid limit and water content were prepared for the suction test. Those samples were prepared by blending two types of bentonite (see Table 2) in different mixing ratios. Liquid limit of each soil sample is $50 \%, 60 \%, 70 \%, 80 \%, 90 \%, 100 \%$, respectively. Each mixing ratio is shown in Table 3.

Table 1: Property of Sample of Deep-sea Mud

(Ministry of Economy, Trade and Industry in Japan, 2016)

\begin{tabular}{|c|c|c|c|}
\hline & $\begin{array}{c}\text { Density } \\
\left(\mathrm{g} / \mathrm{cm}^{3}\right)\end{array}$ & $\begin{array}{c}\text { Liquid limit } \\
(\%)\end{array}$ & $\begin{array}{c}\text { Water Content } \\
(\%)\end{array}$ \\
\hline A-1 & 2.850 & 116.3 & 124.1 \\
\hline A-2 & 2.831 & 111.1 & 138.9 \\
\hline A-3 & 2.792 & 98.7 & 156.3 \\
\hline A-4 & 2.792 & 105.4 & 140.3 \\
\hline B & 2.833 & 117.1 & 128.8 \\
\hline C & 2.821 & 109.8 & 146.1 \\
\hline
\end{tabular}

Table 2: Property of Bentonite

\begin{tabular}{|c|c|c|}
\hline & $\begin{array}{c}\text { Density } \\
\left(\mathrm{g} / \mathrm{cm}^{3}\right)\end{array}$ & $\begin{array}{c}\text { Liquid limit } \\
(\%)\end{array}$ \\
\hline Bentonite I & 2.507 & 48.84 \\
\hline Bentonite II & 2.661 & 110.01 \\
\hline
\end{tabular}

Table 3: Mixing Ratio and Liquid Limit of Sediments

\begin{tabular}{|c|c|c|c|}
\hline & $\begin{array}{c}\text { Liquid limit } \\
(\%)\end{array}$ & \multicolumn{2}{c|}{ Mixing ratio (\%) } \\
\cline { 3 - 4 } & 50 & 99.06 & I \\
\hline $\mathrm{W}_{\mathrm{L}}=50$ & 60 & 80.50 & 19.50 \\
\hline $\mathrm{W}_{\mathrm{L}}=60$ & 70 & 61.94 & 38.06 \\
\hline $\mathrm{W}_{\mathrm{L}}=70$ & 80 & 43.38 & 56.62 \\
\hline $\mathrm{W}_{\mathrm{L}}=80$ & 90 & 24.82 & 75.18 \\
\hline $\mathrm{W}_{\mathrm{L}}=90$ & 100 & 6.26 & 93.74 \\
\hline $\mathrm{W}_{\mathrm{L}}=100$ & &
\end{tabular}

\subsection{Suction Test}

A conceptual diagram of the suction test is shown in Figure 2. The sediment samples which arranged the water contents from $60 \sim 160 \%$ were filled into the plastic box. In the suction test, the ratio of water content and liquid limit $\left(W_{C} / W_{L}\right)$ was defined to evaluate the fluidity of sediment samples quantitatively. The water content/liquid limit ratio of the sediment samples is from $1.00 \sim 1.85$. The length, width, and height of the sediments are 155 $\mathrm{mm}, 50 \mathrm{~mm}$, and $130 \mathrm{~mm}$, respectively. The sediments are vacuumed with a suction pump from the center of the surface of the sediments. The suction pressure of the pump is adjusted to 4.0 $\mathrm{kPa}$ (maximum suction pressure of the pump is $21.4 \mathrm{kPa}$ ). The 
diameter of the suction pump is $10 \mathrm{~mm}$ and the duration of suction is 8 seconds. The suction target is $50 \mathrm{~mm}$ depth from the simulated soil surface, meaning that the pump moves downward in 6.25 $\mathrm{mm} / \mathrm{sec}$ from the surface of the sediments. At the end of the test, the suction volume and deformed shape were measured to evaluate the deformation behavior of the sediment samples. The deformed shape of sediment samples is identified by measuring the maximum vertical length $(V)$ and horizontal length $(H)$ of the deformation area. Besides, the span of influence was defined as $H / V$ as a normalized parameter to show the deformation behavior.

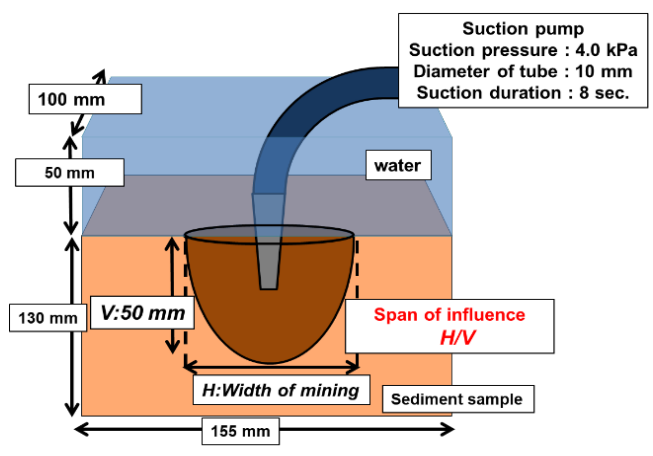

Figure 2: Conceptual Diagram of Suction Test

\subsection{Results and Discussion}

Figure 3 shows the relation of the ratio of water content/liquid limit and suction volume. Suction volume increases exponentially with an increase of the water content/liquid limit ratio: its volume is $18-70 \mathrm{~mL}$ when $\mathrm{W}_{\mathrm{C}} / \mathrm{W}_{\mathrm{L}}$ is 1.0 while its volume increases to $194-$ $533 \mathrm{~mL}$ when $\mathrm{W}_{\mathrm{C}} / \mathrm{W}_{\mathrm{L}}$ is 1.7 . Figure 4 shows the relation of the water content/liquid limit ratio and span of influence. The span of influence also increases with an increase of water content/liquid limit ratio. It is seemingly categorized into 3 parts: $\mathrm{H} / \mathrm{L}$ is around 1.0 when the $\mathrm{W}_{\mathrm{C}} / \mathrm{W}_{\mathrm{L}}$ is less than $1.3, \mathrm{H} / \mathrm{L}$ is around 2.0 when the $\mathrm{W}_{\mathrm{C}} / \mathrm{W}_{\mathrm{L}}$ is from 1.3-1.6, and $\mathrm{H} / \mathrm{L}$ is more than 2.0 when the $\mathrm{W}_{\mathrm{C}} / \mathrm{W}_{\mathrm{L}}$ is more than 1.6. From the aspect of deformation behavior of sediment samples, the behavior can be classified into 3 types; sharp deformation, cone-shaped deformation, gentle circular arc deformation as shown in Figure 5. In comparison with the water content/liquid limit ratio and the span of influence, the deformation behavior can be defined with the water content/liquid limit ratio. It is respectively categorized as sharp, cone-shaped, and gentle circular arc when the ratio of water content/liquid limit is under 1.3, from 1.3 to 1.6 , and over 1.6. In comparison with deformation behavior and suction volume, the suction volume is small when the deformation behavior is sharp. This result indicates that less sediments can be recovered in the limited area at one time, meaning that the efficiency of seabed suction mining is expected to be small although the environmental impact is also expected to be small because the span of influence is small. On the other hand, the suction quantity is large when the deformation behavior is a gentle circular arc. This result indicates that many sediments can be recovered in a wide range at one time, indicating that the efficiency of seabed suction mining is expected to be large whereas the environmental impact is also large.

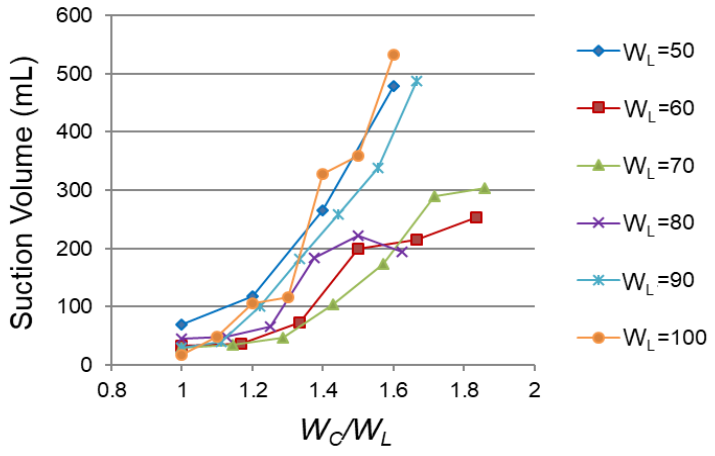

Figure 3: Relation of $W_{C} / W_{L}$ and Suction Volume

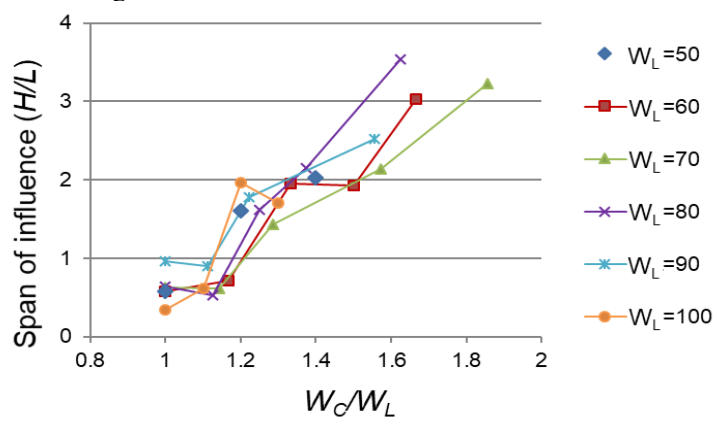

Figure 4: Relation of $W_{C} / W_{L}$ and Span of Influence

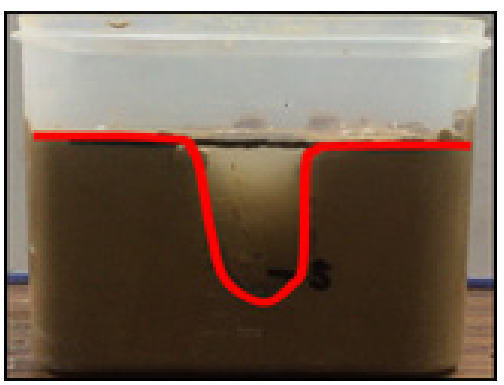

(a) $\mathrm{W}_{\mathrm{C}} / \mathrm{W}_{\mathrm{L}}<1.3$ (sharp)

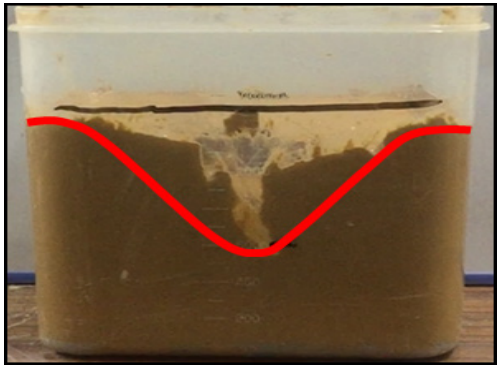

(b) $\mathrm{W}_{\mathrm{C}} / \mathrm{W}_{\mathrm{L}}=1.3 \sim 1.6$ (cone-shaped)

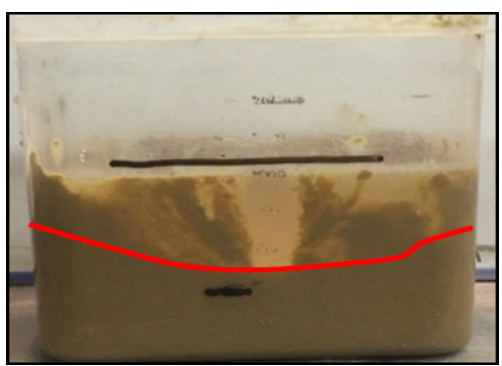

(c) $\mathrm{W}_{\mathrm{C}} / \mathrm{W}_{\mathrm{L}}>1.6$ (gentle circular arc)

Figure 5: Classified of Deformation Behavior of Sediment Sample 


\section{Application of Sealants as Surface Cover}

\subsection{Sealants}

It is important to evaluate and consider the environmental impact properly. At present, deformation of seafloor and diffusion of the suspended particle is concerned while the environmental standard has not been established yet in seabed resources mining. Sealants are considered as one of the methods to reduce environmental impact in seabed mining. The sealants are based on ground improvement techniques and enhanced anti-washout ability under the water. The technique is commonly used to improve ground stability by injecting cement [20]. In addition, these materials are also utilized for restraining the elution of detrimental substances by covering mining areas as stated previously [21]. Figure 6 shows the conceptual diagram of seabed suction mining covered with sealants. These materials are, additionally, able to react along the line of deformation of landforms and cracks because of their viscosity. From these considerations, it is expected to prevent the diffusion of toxic materials on the seafloor and protect environmental effects and collapse of the ground by applying sealants as a surface cover in seabed mining [22]. In this study, slag-type sealants which contain slag, polycarboxylic ether, superplasticizer, and hydroxyethyl cellulose are used [23]. The water/powder ratio is $30 \%$.

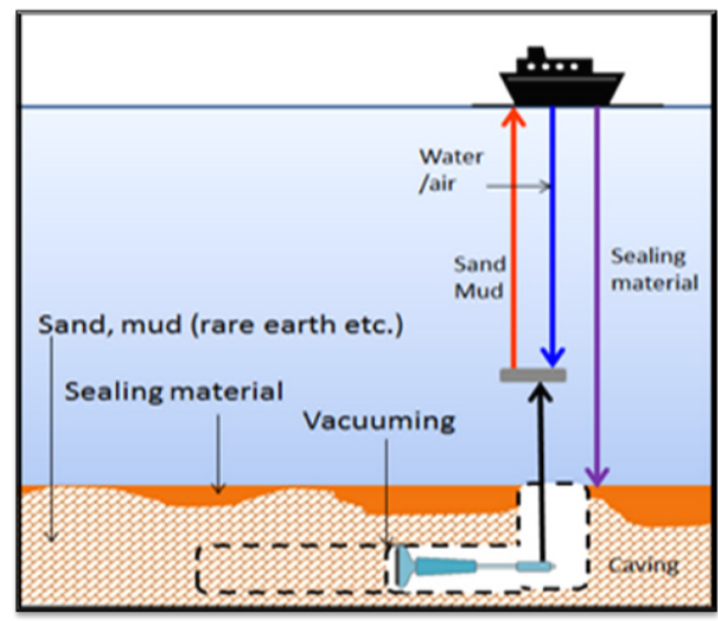

Figure 6: Conceptual Diagram of Seabed Suction Mining

\subsection{Covering Test}

The sealants have to be covered on the surface of the sediments to reduce environmental disturbance. However, it is suspected to sink the sealants into the sediments due to their weight. Therefore, the covering test using sediment samples and sealants was conducted to investigate the effectiveness of surface covering with sealants. In this test, the sealants are poured into the surface of the sediment samples with a funnel. The thickness covered by the sealants was $10 \mathrm{~mm}$. The sediment sample is prepared with a lower density; the density is $1.23 \mathrm{~g} / \mathrm{cm}^{3}$ and $W_{C} / W_{L}$ is 1.7 . The conceptual diagram of the covering test is shown in Figure 7. The sealants which have the different density $\left(1.25 \sim 1.60 \mathrm{~g} / \mathrm{cm}^{3}\right)$ were prepared in this test. The density of sealants was arranged with the modification of aggregate weight. The surface area of the container was $28.8 \mathrm{~cm}^{2}$. Additionally, the surface coverage ratio is calculated with the binarization of image analysis. This study uses Image $J$ for the image analysis [24]. Figures 8 show the relation of coverage ratio and the density of sealant. The images were taken from the top of sealants, meaning that the coverage ratio is $100 \%$ if the sealants remain above the sediment sample without sinking. It is clear that the coverage ratio can be improved by decreasing the density of sealants. The surface coverage is approximately $100 \%$ if the density of the sealants is below $1.4 \mathrm{~g} / \mathrm{cm}^{3}$ while the surface coverage is decreased if the density of the sealants is more than $1.5 \mathrm{~g} / \mathrm{cm}^{3}$, meaning that the sinking of the sealants occurs. Considering the density of the simulated sediment is $1.23 \mathrm{~g} / \mathrm{cm}^{3}$, it is possible to suppress the sinking of the sealant by applying the sealant of the same level as the density of sediment samples.

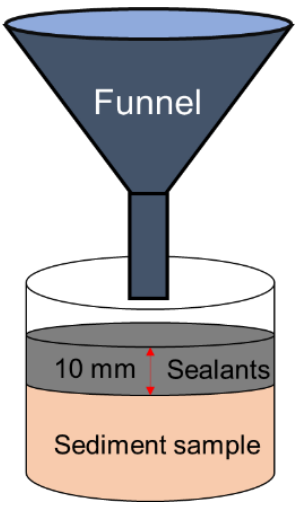

Figure 7: Conceptual Diagram of Covering Test

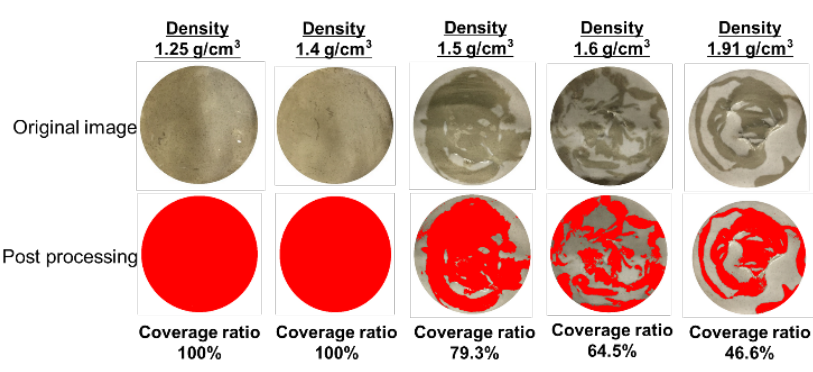

Figure 8: Relation of Density and Coverage Ratio

\subsection{Suction Test with Sealants}

The suction test with sealants was conducted to evaluate the deformation behavior of sediment samples when sealants were applied on the surface. The suction volume and span of influence were measured in this test. The thickness of sealants is $10 \mathrm{~mm}$. Other experimental conditions are the same as the test in the case of sediment samples only. Figure 9 shows the relation of the ratio of water content/liquid limit and suction volume. In either case, suction volume increases with an increase of water content/liquid limit ratio. The suction volume may be less affected with/without sealants while some cases show the decreasing trend: the suction volume shows from $44.76-337.63 \mathrm{~mL}$ without sealants and from $61.19-270.14 \mathrm{~mL}$ with sealants. Figure 10 shows the relation of the 
ratio of water content/liquid limit and span of influence. The span of influence also increases with an increase of water content/liquid limit ratio. Additionally, the span of influence decreases when the surface is covered by sealants: it shows from 1.44-3.54 without sealants and from $0.33-2.27$ with sealants. This might be suspected that the adhesive force between sealants and sediments restraint the movement of sediments surface. As a result, it is indicated that the application of sealants can reduce the environmental impact like suspended particles and topographic variation.

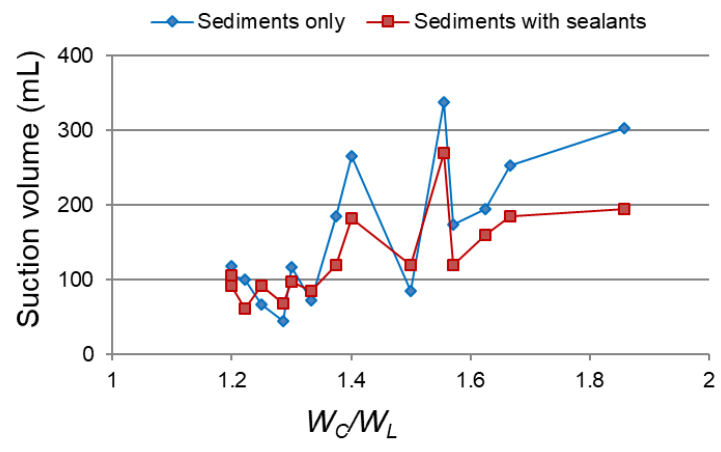

Figure 9: Relation of $W_{C} / W_{L}$ and Suction Volume

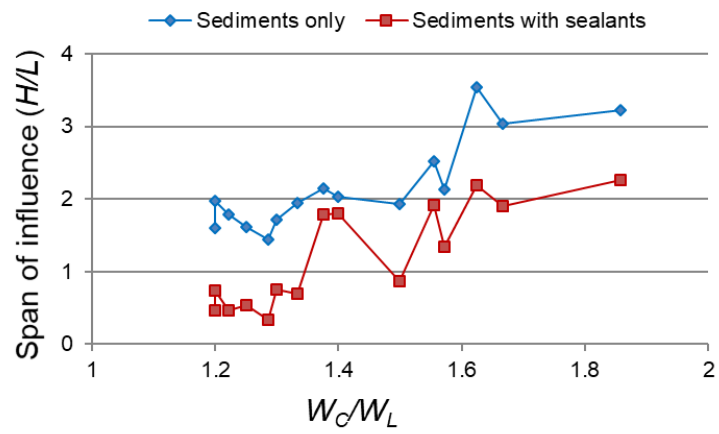

Figure 10: Relation of $W_{C} / W_{L}$ and Span of Influence

\section{Conclusion}

The abundant deep-sea mud which contains rare-earth elements has been found as the seafloor sediments. The development of these untouched resources contributes to a diversification of the supply sources of the rare-earth resources. In this study, the recovery of sediments using seabed suction mining is discussed on a laboratory scale. In the results, the deformation behavior of the sediments with suction mining can be assessed by the ratio of water content/liquid limit. In addition, it is shown that the suction volume increases with the ratio of water content/liquid limit. In addition, the deformation behavior changes to sharp deformation, cone-shaped deformation, and gentle circular arc deformation based on the water content/liquid limit ratio. It is clarified that the coverage decreases when the density of sealants is larger than that of the sediments because the sealants sink into the sediments due to their weight. Therefore, the density of sealants should be arranged to the same level as the density of sediment samples by selecting the proper aggregate. Furthermore, it is indicated that sealants can reduce the environmental impact like suspended particles and topographic variation because adhesive force between sealants and simulated soil restraint the movement of sediments surface.

\section{Conflict of Interest}

The authors declare no conflict of interest.

\section{Acknowledgment}

This work was supported by JSPS KAKENHI Grant Number JP 19K05351.

\section{Reference}

[1] K. Hirai, "Trends in Metal Resource Development and Strategies for Resource Security”, Surface Science for Resource. 35(2), 114-115, 2014, doi: $10.1380 /$ jsssj.35.114.

[2] Y. Kato, K. Fujinaga, K. Nakamura, Y. Takaya, K. Kitamura, J. Ohta, R. Toda, T. Nakashima, H. Iwamori, "Deep-sea mud in the Pacific Ocean as a potential resource for rare-earth elements", Nature Geoscience, 4(8), 535539, 2011, doi: 10.1038/ngeo1185

[3] N. Toro, P. Robles, R.I. Jeldres, "Seabed mineral resources, an alternative for the future of renewable energy: A critical review", Ore Geology Reviews, 126, 2020, doi: 10.1016/j.oregeorev.2020.103699.

[4] R. Motoori, B.C. McLellan, "Resource security strategies and preferences for deep ocean mining from a community survey in Japan", Marine Policy, 128, 2021, doi: 10.1016/j.marpol.2021.104511.

[5] A. Hallgren, A. Hansson, "Conflicting narratives of deep sea mining", Sustainability (Switzerland), 13(9), 2021, doi: 10.3390/su13095261.

[6] W. Leal Filho, I.R. Abubakar, C. Nunes, J. Platje, P.G. Ozuyar, M. Will, G.J. Nagy, A.Q. Al-Amin, J.D. Hunt, C. Li, "Deep seabed mining: A note on some potentials and risks to the sustainable mineral extraction from the oceans", Journal of Marine Science and Engineering, 9(5), 2021, doi: 10.3390/jmse9050521.

[7] A. Jaeckel, "Strategic environmental planning for deep seabed mining in the area", Marine Policy, 114, 2020, doi: 10.1016/j.marpol.2019.01.012.

[8] L.J. Gerber, R.L. Grogan, "Challenges of operationalising good industry practice and best environmental practice in deep seabed mining regulation", Marine Policy, 114, 2020, doi: 10.1016/j.marpol.2018.09.002.

[9] V. Tunnicliffe, A. Metaxas, J. Le, E. Ramirez-Llodra, L.A. Levin, "Strategic Environmental Goals and Objectives: Setting the basis for environmental regulation of deep seabed mining", Marine Policy, 114, 2020, doi: 10.1016/j.marpol.2018.11.010.

[10] J. Hyman, R.A. Stewart, O. Sahin, "Adaptive Management of Deep-Seabed Mining Projects: A Systems Approach", Integrated Environmental Assessment and Management, 2021, doi: 10.1002/ieam.4395.

[11] M. Squillace , "Best regulatory practices for deep seabed mining: Lessons learned from the U.S. Surface Mining Control and Reclamation Act", Marine Policy, 125, 2021, doi: 10.1016/j.marpol.2020.104327.

[12] W. Kong, "Design of dredging device for immersed gravel bed and analysis of water jet", in 2021 7th International Symposium on Mechatronics and Industrial Informatics, ISMII 2021， 52-56, 2021, doi: 10.1109/ISMII52409.2021.00018.

[13] Y. Zhang, J. Song, "Study on fluidization process in jet flow dredging device and the effects of device structure to sand collecting performance", in IOP Conference Series: Materials Science and Engineering, 2020, doi: 10.1088/1757-899X/892/1/012117.

[14] M.K. Sarkar, S. Sarkar, "Assisting pumps for dredging", Lecture Notes in Civil Engineering, 23, 571-579, 2007, doi: 10.1007/978-981-13-3134-3_43.

[15] T. Yamanaka, K. Maeto, H. Akashi, J. Ishibashi, Y. Miyoshi, K. Okamura, T. Noguchi, Y. Kuwahara, T. Toki, U. Tsunogai, T. Ura, T. Nakatani, T. Maki, K. Kubokawa, H. Chiba, "Shallow submarine hydrothermal activity with significant contribution of magmatic water producing talc chimneys in the Wakamiko Crater of Kagoshima Bay, southern Kyushu, Japan”, Journal of Volcanology and Geothermal Research, 258, 74-84, 2013, doi: 10.1016/j.jvolgeores.2013.04.007.

[16] H. Sakamoto, "The Distribution of Mercury, Arsenic, and Antimony in Sediments of Kagoshima Bay", Bulletin of the Chemical Society of Japan, 58, 580-587, 1985, doi: 10.1246/bcsj.58.580.

[17] K. Takahashi, T. Yamanaka, H. Shimada, T. Sasaoka, A. Hamanaka, "Application of Cement-based Sealants for Prevention and Remediation of Environmental Impact of Submarine Resource Mining", in 26th International Symposium on Mine Planning and Equipment Selection, 363- 
367,2017

[18] M. Kobayashi, K. Takahashi, Y. Kawabata, "Physicochemical properties of the Portland cement-based mortar exposed to deep seafloor conditions at a depth of 1680 m", Cement and Concrete Research, 2021, doi: 10.1016/j.cemconres.2020.106335.

[19] K. Takahashi, Y. Kawabata, M. Kobayashi, S. Gotoh, S. Nomura, T. Kasaya, M. Iwanami, "Action of Hydraulic Pressure on Portland Cement Mortars Current Understanding and Related Progress of the First-Ever In-Situ Deep Sea Tests at a $3515 \mathrm{~m}$ Depth", Journal of Advanced Concrete Technology, 19, 226-239, 2021, doi: 10.3151/jact.19.226.

[20] H. Shimada, A. Hamanaka, T. Sasaoka, K. Matsui, "Development of Injection Material for Offshore Structures Using Flyash-Surfactant Mixtures", Development and Applications of Oceanic Engineering , 2(3), 70-76, 2013.

[21] R.A, Wuana, F.E. Okieimen, Heavy metals in contaminated soils: A review of sources, chemistry, risks, and best available strategies for remediation, Apple Academic Press, 2014.

[22] S. Sakamoto, S. Matsumoto, T. Sasaoka, H. Shimada, S. Fujita, K. Takahashi, "Fundamental Study on Deformation Behavior of Seafloor Covered with Sealing Materials in Seabed Mining", in International Symposium on Earth Science and Technology 2016, 74-78, 2016.

[23] H. Shimada, T. Sasaoka, S. Fujita, S. Wahyudi, Y. Yoshida, "Construction of seabed structures by new development covering material using fly ash", Inzynieria Mineralna, 17(1), 143-151, 2016, doi: 10.29227/IM-2016-01-22.

[24] J. Schindelin, I. Arganda-Carreras, E. Frise, V. Kaynig, M. Longair, T. Pietzsch, S. Preibisch, C. Rueden, S. Saalfeld, B. Schmid, J.-Y. Tinevez, D.J. White, V. Hartenstein, K. Eliceiri, P. Tomancak, A. Cardona, "Fiji: An opensource platform for biological-image analysis", Nature Methods, 9(7), 676682, 2012, doi: 10.1038/nmeth.2019. 